\title{
UTILIZAÇÃO DE EXTRATO DE COGUMELO COMOANTIOXIDANTE NATURAL EM ÓLEO VEGETAL
}

\author{
Use of mushroom extract as natural antioxidant in vegetal oil
}

\author{
Ana Carolina da Silva ${ }^{1}$, Marcel de Campos Oliveira ${ }^{1}$, Patrícia Vieira Del Ré ${ }^{1}$, Neuza Jorge ${ }^{2}$
}

\begin{abstract}
RESUMO
Conduziu-se este trabalho, com o objetivo de avaliar a atividade antioxidante de diferentes extratos de cogumelo Agaricus blazei, bem como a estabilidade oxidativa do óleo de soja adicionado de extrato de cogumelo. $\mathrm{O}$ cogumelo seco em estufa a $55^{\circ} \mathrm{C}$ e triturado $(10 \mathrm{~g})$ fui submetido à extração, à temperatura ambiente, com $100 \mathrm{~mL}$ de metanol e metanol:água (1:1) com duração de 6 e 12 horas para ambas as extrações. O extrato de maior atividade antioxidante, conforme o método DPPH, foi aplicado em óleo de soja na concentração de $0,1 \%$ de compostos fenólicos totais e, então, submetido ao método do Rancimat e ao teste acelerado em estufa a $60^{\circ} \mathrm{C}$ por um período de 16 dias. Amostras de óleo foram retiradas da estufa cada 4 dias e analisadas quanto ao índice de peróxidos e dienos conjugados. Como parâmetros de comparação, foram utilizados os antioxidantes sintéticos BHT (100 mg/kg), TBHQ (50 mg/ $\mathrm{kg}$ ) e o óleo de soja isento de antioxidantes (controle). Os resultados demonstraram que o extrato metanólico:aquoso, com 6 horas de extração, apresentou maior atividade antioxidante. A aplicação desse extrato em óleo de soja proporcionou a seguinte ordem em relação à estabilidade oxidativa: TBHQ > extrato de cogumelo > BHT = óleo de soja (controle). O extrato de cogumelo também foi eficiente em relação à formação de peróxidos e dienos conjugados que, apesar de aumentarem ao longo do tempo, foi menor que o BHT, porém maior que o TBHQ. O extrato de cogumelo apresentou-se efetivo na proteção do óleo, podendo ser considerado um potencial antioxidante natural.
\end{abstract}

Termos para indexação: Antioxidantes, cogumelo, estabilidade oxidativa, óleo de soja.

\section{ABSTRACT}

The present paper had the objectives of measuring the antioxidant activity of different extracts of the mushroom Agaricus blaze $i$ and evaluating the oxidative stability of soybean oil added with the mushroom extract. The mushroom dried in stove at $55^{\circ} \mathrm{C}$ and ground $(10 \mathrm{~g})$ was submit to extraction with $100 \mathrm{~mL}$ methanol and methanol:water (1:1) for six and 12 hours, respectively, at room temperature. The extract with the highest antioxidant activity, according to the DPPH method, was added to the soybean oil at the concentration of $0.1 \%$ total phenolic compounds and then submitted to the Rancimat method and to the accelerated test in stove at $60^{\circ} \mathrm{C}$ for 16 days. Samples of oil were withdrawn every four days and the rate of peroxides and conjugated dienes were analyzed. The synthetic antioxidants BHT $(100 \mathrm{mg} / \mathrm{kg})$, TBHQ $(50 \mathrm{mg} / \mathrm{kg})$, and antioxidant-free soybean oil (control) were used as comparison parameters. The results showed that the methanol:water extract resulting from six hours of extraction presented the highest antioxidant activity. The oxidative stability of the mushroom extract, the synthetic antioxidants, and the control followed the sequence: TBHQ $>$ mushroom extract $>$ BHT $=$ soybean oil (control). The mushroom extract was also efficient regarding the formation of peroxides and conjugated dienes. Despite the increase of these compounds over the time, the extract was less efficient than BHT and more efficient than TBHQ. The mushroom extract has shown effective in the protection of the oil, bearing the potential of a natural antioxidant.

Index terms: Antioxidants, mushroom, oxidative stability, soybean oil.

(Recebido em 19 de junho de 2008 e aprovado em 21 de janeiro de 2009)

\section{INTRODUÇÃO}

Os antioxidantes estão presentes de forma natural ou intencional nas gorduras e alimentos, com o objetivo de retardar a oxidação lipídica, mantendo intactas suas características sensoriais.

O consumo de aditivos sintéticos na prevenção da oxidação lipídica tem sido alvo de constante preocupação quanto à sua inocuidade, motivando a busca de antioxidantes naturais que possam substitui-los total ou parcialmente. Por esta razão, maior atenção tem sido dada para aplicação de antioxidantes naturais em alimentos, por causa dos potenciais efeitos terapêutico e nutricional (Gaméz-Meza et al., 1999).

Várias fontes de antioxidantes naturais são conhecidas e algumas são amplamente encontradas no reino vegetal. Seu poder antioxidante muitas vezes é atribuído aos compostos fenólicos, essenciais no

\footnotetext{
'Alunos do Programa de Pós-Graduação em Engenharia e Ciência de Alimentos, Instituto de Biociências, Letras e Ciências Exatas, Universidade Estadual Paulista - UNESP. Rua Cristóvão Colombo, nํ. 2265, Jd. Nazareth, CEP 15054-000, São José do Rio Preto-SP - carolzesilva@yahoo.com.br, marceloliveira.oliveira@bol.com.br, delre@unirp.edu.br

${ }^{2}$ Professora Adjunta do Departamento de Engenharia e Tecnologia de Alimentos - IBILCE - UNESP. Rua Cristóvão Colombo, nº. 2265, Jd. Nazareth, CEP 15054-000, São José do Rio Preto-SP - njorge@ibilce.unesp.br
} 
crescimento das plantas e eficientes na prevenção da autoxidação (Angelo \& Jorge, 2007).

Os cogumelos são considerados por muitos pesquisadores como alimentos nutracêuticos ou funcionais fisiológicos, fato que tem estimulado também os produtores brasileiros na busca de técnicas mais produtivas e na introdução de novas espécies. A utilização de certas espécies, em forma de chás ou cápsulas, como preventivo de algumas doenças, também acelerou a produção de cogumelos (Furlani \& Godoy, 2005).

São conhecidas cerca de 2.000 espécies de cogumelos potencialmente comestíveis, porém, apenas 25 delas são normalmente utilizadas na alimentação humana e um número ainda menor tem sido comercialmente cultivado (Coutinho, 2007).

O Agaricus blazei, um cogumelo nativo do Brasil, vem sendo cultivado, comercialmente, desde o início da década de 1990 e a maior produção encontra-se no estado de São Paulo, onde o cultivo é feito nas épocas de primavera e verão (Braga et al., 1998). Segundo Mizuno et al. (1990), o basidiocarpo de A. blazei apresenta 40-45\% de proteínas, $38-45 \%$ de carboidratos, $6-8 \%$ de fibras, $5-7 \%$ de minerais e 3-5\% de gordura, valores baseados em relação à matériaseca. Contêm ainda as vitaminas B1, B2 e niacina e teores elevados de potássio e cálcio.

Essa espécie popularmente conhecida como cogumelo-do-sol tem sido amplamente consumida em diferentes partes do mundo em razão das suas propriedades medicinais, sendo utilizada como alimento funcional para prevenção de diversas doenças (Di Piero, 2003). O A. blazei apresenta várias propriedades como ações antimutagênica, bactericida e estimulante das atividades imunológicas do organismo humano (Teixeira, 1999), além da presença de diversos compostos anti-tumorais (Kawagishi et al., 1990; Takaku et al., 2001; Nakajima et al., 2002).

Compostos fenólicos parecem ser os Principais componentes responsáveis pela atividade antioxidante de extratos de cogumelo (Elmastas et al., 2007). Segundo Tsai et al. (2007), a propriedade antioxidante do cogumelo $A$. blazei pode estar associada à sua alta concentração de tocoferóis.

Apesar da grande biodiversidade existente no Brasil e de haver um grande potencial a ser explorado, existem poucos dados sobre atividade antioxidante de extratos de cogumelos. Assim, neste trabalho, objetivou-se avaliar a atividade antioxidante de diferentes extratos de cogumelo A. blazei, bem como a estabilidade oxidativa do óleo de soja adicionado de extrato de cogumelo.

\section{MATERIALE MÉTODOS}

Para a realização do experimento foi utilizado óleo de soja refinado, fabricado pela empresa Cargill Agrícola S/A sem conservantes, adquirido no comércio local.

O cogumelo A. blazei foi adquirido da Universidade Estadual Paulista - UNESP, Faculdade de Engenharia de Ilha Solteira, campus de Ilha Solteira-SP. Após a colheita, o cogumelo A. blazei, in natura, foi seco em estufa a $55^{\circ} \mathrm{C}$ e triturado, resultando num pó homogêneo, o qual foi embalado em pote de plástico e fechado com tampa até a realização das análises.

Os extratos de cogumelo foram obtidos por processo de extração com metanol e metanol:água (1:1). Para cada extrato, $100 \mathrm{~mL}$ do solvente foram adicionados a $10 \mathrm{~g}$ de amostra. O processo de extração ocorreu sob agitação contínua em um shaker, à temperatura ambiente, em dois diferentes tempos, 6 e 12 horas. Em seguida, a mistura foi centrifugada a $3.000 \mathrm{rpm}$ por 5 minutos e o sobrenadante filtrado. Os solventes, metanol e metanol:água (1:1), utilizados para a obtenção dos extratos foram removidos sob pressão reduzida a 40 e $50^{\circ} \mathrm{C}$, respectivamente, com vistas a calcular o rendimento de extrato seco.

A atividade antioxidante dos extratos de cogumelo foi determinada pelo método do radical DPPH (2,2-difenilpicril-hidrazila), descrito por Brand-Williams et al. (1995). DPPH é um radical livre estável que aceita um elétron ou um radical hidrogênio para tornar-se uma molécula dimagnética estável e, desta forma, é reduzido na presença de um antioxidante. Os solventes, metanol e metanol:água (1:1), empregados para a obtenção dos extratos foram utilizados, em separado para o preparo das soluções. Inicialmente, preparou-se uma solução para cada solvente com concentração de $500 \mathrm{ìg} / \mathrm{mL}$ de extrato de cogumelo $A$. blazei. Cada amostra desta solução $(0,3 \mathrm{~mL})$ foi adicionada a 2,7 mL de solução de DPPH (40 ìg/mL) em diferentes concentrações $(5,10,25,50,125,250,350$ e $500 \mathrm{mg} / \mathrm{mL})$. Após o tempo de reação de 30 minutos, a absorbância foi lida em $515 \mathrm{~nm}$ e convertida em porcentagem de atividade antioxidante $\left(\mathrm{AA}_{\text {máxima }}\right)$ por meio da seguinte fórmula:

$$
\mathrm{AA}_{\text {máxima }}(\%)=100-\left\{\left[\left(\mathrm{Abs}_{\text {amostra }}-\mathrm{Abs}_{\text {branco }}\right) \times 100\right] / \mathrm{Abs}_{\text {controle }}\right\}
$$

Um controle foi feito com $2,7 \mathrm{~mL}$ de DPPH e o branco realizado com $0,3 \mathrm{~mL}$ de solução metanólica:aquosa ou metanólica do extrato e $2,7 \mathrm{~mL}$ do respectivo solvente, para cada concentração.

A quantificação de compostos fenólicos totais foi determinada por espectrofotometria, por meio do reagente de Folin-Ciocalteu, segundo a metodologia descrita por 
Singleton \& Rossi (1965), que se baseia na redução dos ácidos fosfomolibídico e fosfotunguístico em solução alcalina. A cor azul produzida pela redução do reagente Folin-Ciocalteu pelos fenólicos é medida espectrofotometricamente, no comprimento de onda de 765 nm. Para a quantificação foi realizada curva padrão, utilizando o ácido gálico nas concentrações de 0 a $500 \mathrm{mg} /$ $\mathrm{L}$, sendo o coeficiente de determinação $\mathrm{R}^{2}=0,9986$, e o resultado foi expresso em miligramas de equivalentes de ácido gálico por grama de extrato $(\mathrm{mg} / \mathrm{g})$.

Para a avaliação da atividade antioxidante do extrato de cogumelo em óleo de soja, foram preparadas amostras misturando o extrato de cogumelo de maior atividade antioxidante com o óleo de soja na concentração de $0,1 \%$ de compostos fenólicos. TBHQ (50 mg/kg) e BHT (100 mg/kg), bem como o óleo de soja isento de antioxidantes (controle) foram utilizados como parâmetros de comparação.

Dois métodos foram empregados para medir a atividade antioxidante do extrato aplicado no óleo de soja: medida da estabilidade oxidativa e teste acelerado em estufa associado com a determinação do índice de peróxidos e dienos conjugados.

A medida da estabilidade oxidativa foi conduzida conforme método proposto pela American Oil Chemists Society-AOCS (1993) que utiliza o equipamento Rancimat, e se baseia na determinação da condutividade elétrica dos produtos voláteis de degradação. A determinação foi realizada a $100^{\circ} \mathrm{C}$, com fluxo de ar de $20 \mathrm{~L} / \mathrm{h}$, com utilização de $3 \mathrm{~g}$ de amostra e volume de água destilada de $60 \mathrm{~mL}$ nos frascos contendo os eletrodos. Por esse método uma curva de condutividade elétrica $\mathrm{x}$ tempo é automaticamente registrada com o decorrer da reação e do teste, sendo o período de indução expresso em horas.

No teste acelerado em estufa, amostras com $20 \mathrm{~mL}$ de óleo de soja foram mantidas sob aquecimento em estufa com circulação de ar a $60^{\circ} \mathrm{C}$ por 16 dias. A cada 4 dias, amostras foram retiradas e analisadas quanto ao índice de peróxidos e dienos conjugados, conforme métodos propostos pela AOCS (1993), cujos resultados foram expressos em meq/kg de amostra e porcentagem, respectivamente.
Os ensaios experimentais foram realizados no delineamento inteiramente casualizado (Banzatto \& Kronka, 2006), cujos resultados obtidos das determinações analíticas, em duplicata, foram submetidos à análise de variância e as diferenças entre as médias testadas a 5\% de probabilidade, pelo teste de Tukey, por meio do programa ESTAT, versão 2.0 (UNESP, 1999).

\section{RESULTADOS E DISCUSSÃO}

O processo de extração utilizado permitiu a obtenção de compostos de elevada polaridade, em função dos diferentes solventes utilizados. A Tabela 1 apresenta o rendimento porcentual dos extratos obtidos após a remoção do solvente orgânico empregado no processo de extração e a atividade antioxidante máxima pelo método DPPH.

As extrações metanólicas:aquosas $(1: 1)$ apresentaram maior rendimento $(41,4 \%)$ quando comparadas às extrações metanólicas, comprovando a influência do solvente. Segundo Keinänen (1993), a utilização de material previamente desidratado pode maximizar a eficiência do processo de extração, assim como a composição química do substrato e a técnica de extração (Dapkevicius et al., 1998).

Julkunen-Tiitto (1985) alega que alimentos com predominância de compostos fenólicos apresentam maior rendimento no processo de extração com solventes polares, em razão da solubilidade. Assim, justifica-se que a adição de água no processo de extração potencializou o rendimento do extrato.

Em relação à atividade antioxidante, o extrato metanólico-aquoso (1:1) referente ao tempo de extração de 6 horas, apresentou o maior valor (28,9\%). Tsai et al. (2007), estudando a eficiência do extrato de cogumelo A. blazei em diferentes solventes, constataram que a atividade antioxidante foi superior quando extraído com água aquecida, atingindo valores médios de 66,3\%.

Uma vez constatada a maior ação antioxidante no extrato metanólico-aquoso (1:1) com 6 horas de extração, passou-se à quantificação dos compostos fenólicos nele

Tabela 1 - Determinação de rendimento e atividade antioxidante $\left(\mathrm{AA}_{\text {máxima }}\right.$ ) dos extratos de cogumelo A. blazei.

\begin{tabular}{lccc}
\hline \multicolumn{1}{c}{ Extrato } & Tempo de Extração (horas) & Rendimento $(\%)$ & AA $_{\text {máxima }}(\%)$ \\
\hline Metanólico & 6 & 15,4 & 26,3 \\
Metanólico & 12 & 16,0 & 27,8 \\
Metanólico:Aquoso (1:1) & 6 & 41,4 & 28,9 \\
Metanólico:Aquoso (1:1) & 12 & 34,1 & 26,6 \\
\hline
\end{tabular}


presentes. A concentração obtida foi de $15 \mathrm{mg} / \mathrm{g}$ de compostos fenólicos totais, valor superior à Tsai et al. (2007), que obtiveram no extrato aquoso de A. blazei 5,67 $\mathrm{mg} / \mathrm{g}$ de compostos fenólicos.

A Tabela 2 apresenta os resultados da avaliação da medida da estabilidade oxidativa do óleo de soja enriquecido com antioxidantes. Observa-se que dentre os agentes antioxidantes adicionados ao óleo de soja, o TBHQ apresentou maior estabilidade oxidativa quando comparado aos demais (BHT e EC), sendo a diferença evidenciada estatisticamente, conforme teste de Tukey $(p<0,05)$. Entretanto, o período de indução do extrato de cogumelo (EC) foi maior que o BHT, demonstrando que o extrato de cogumelo pode ser um potencial antioxidante natural.

Gámez-Meza et al. (1999), aplicando concentração de $0,1 \%$ de compostos fenólicos em óleo de soja, extraídos de sementes de uva, encontraram valores de período de indução de $15,2 \mathrm{~h}$ a $110^{\circ} \mathrm{C} / 20 \mathrm{~L} / \mathrm{h}$, inferior ao extrato de cogumelo avaliado neste trabalho $(20,4 \mathrm{~h})$.
Na Tabela 3, apresentam-se os resultados da avaliação de índice de peróxidos e dienos conjugados para óleo de soja durante estocagem.

De acordo com a Tabela 3 , observa-se que a formação de peróxidos aumentou ao longo do tempo para todos os Tratamentos. $\mathrm{O}$ antioxidante TBHQ protegeu mais o óleo com menor formação de peróxidos, seguido pelo extrato de cogumelo e BHT. Essa proteção apresentou-se mais significativa a partir de 8 dias de estocagem, já que, até 4 dias, não houve diferença significativa entre os Tratamentos.

As normas que regulamentam a adequação de óleo para o consumo no Brasil, segundo a Portaria 482/99ANVISA, estabelecem o máximo de $10 \mathrm{meq} / \mathrm{kg}$ de índice de peróxidos para o óleo de soja refinado (Brasil, 1999). Neste trabalho, o óleo de soja (controle) e o tratamento com BHT, a partir de 8 dias de estocagem, apresentaram valores acima deste limite. No entanto, o óleo de soja com extrato de cogumelo foi eficiente até 12 dias de estocagem.

Tabela 2 - Médias da estabilidade oxidativa do óleo de soja enriquecido com antioxidantes.

\begin{tabular}{lc}
\hline \multicolumn{1}{c}{ Tratamentos } & Estabilidade oxidativa (horas) \\
\hline Óleo de soja (controle) & $15,9^{\mathrm{c}}$ \\
Óleo de soja + TBHQ & $27,3^{\mathrm{a}}$ \\
Óleo de soja + BHT & $16,6^{\mathrm{c}}$ \\
Óleo de soja + EC & $20,4^{\mathrm{b}}$ \\
\hline
\end{tabular}

TBHQ: $50 \mathrm{mg} / \mathrm{kg}$; BHT: $100 \mathrm{mg} / \mathrm{kg}$; EC: extrato de cogumelo (0,1\% de fenólicos totais).

a,b,c... (coluna) - em cada tratamento, médias seguidas de mesma letra minúscula não diferem pelo teste de Tukey $(\mathrm{p}>0,05)$.

Tabela 3 - Médias de índice de peróxidos e dienos conjugados para óleo de soja durante estocagem.

\begin{tabular}{|c|c|c|c|c|c|}
\hline \multirow[t]{2}{*}{ Tratamentos } & \multicolumn{5}{|c|}{ Tempo de estocagem (dias) } \\
\hline & 0 & 4 & 8 & 12 & 16 \\
\hline \multicolumn{6}{|c|}{ Índice de peróxidos (meq/kg) } \\
\hline Óleo de soja (controle) & $1,61^{\mathrm{dA}}$ & $3,47^{\mathrm{dA}}$ & $45,62^{\mathrm{cA}}$ & $105,00^{\mathrm{bA}}$ & $132,58^{\mathrm{aA}}$ \\
\hline Óleo de soja + TBHQ & $0,72^{\mathrm{bA}}$ & $2,36^{\mathrm{abA}}$ & $2,87^{\mathrm{abC}}$ & $4,57^{\mathrm{abC}}$ & $7,48^{\mathrm{aD}}$ \\
\hline Óleo de soja + BHT & $0,74^{\mathrm{dA}}$ & $3,23^{\mathrm{dA}}$ & $34,87^{\mathrm{cB}}$ & $81,75^{\mathrm{bB}}$ & $125,03^{\mathrm{aB}}$ \\
\hline Óleo de soja + EC & $1,34^{\mathrm{bA}}$ & $3,33^{\mathrm{bA}}$ & $4,36^{\mathrm{bC}}$ & $5,95^{\mathrm{bC}}$ & $27,00^{\mathrm{aC}}$ \\
\hline \multicolumn{6}{|l|}{ Dienos conjugados $(\%)$} \\
\hline Óleo de soja (controle) & $0,28^{\mathrm{eA}}$ & $0,31^{\mathrm{dB}}$ & $0,60^{\mathrm{cA}}$ & $1,18^{\mathrm{bA}}$ & $1,54^{\mathrm{aA}}$ \\
\hline Óleo de soja + TBHQ & $0,28^{\mathrm{bA}}$ & $0,29^{\mathrm{bB}}$ & $0,31^{\mathrm{abC}}$ & $0,31^{\mathrm{abC}}$ & $0,32^{\mathrm{aD}}$ \\
\hline Óleo de soja + BHT & $0,28^{\mathrm{dA}}$ & $0,30^{\mathrm{dB}}$ & $0,56^{\mathrm{cB}}$ & $0,90^{\mathrm{bB}}$ & $1,31^{\mathrm{aB}}$ \\
\hline Óleo de soja + EC & $0,28^{\mathrm{cA}}$ & $0,34^{\mathrm{bA}}$ & $0,33^{\mathrm{bC}}$ & $0,32^{\mathrm{bC}}$ & $0,51^{\mathrm{aC}}$ \\
\hline
\end{tabular}

TBHQ: $50 \mathrm{mg} / \mathrm{kg}$; BHT: $100 \mathrm{mg} / \mathrm{kg}$; EC: extrato de cogumelo (0,1\% de fenólicos totais).

a,b... (linha) - em cada tratamento, médias seguidas de mesma letra minúscula não diferem pelo teste de Tukey $(\mathrm{p}>0,05)$.

A,B... (coluna) - em cada tempo de estocagem, médias seguidas de mesma letra maiúscula não diferem pelo teste de Tukey $(\mathrm{p}>0,05)$. 
Como observado na Tabela 3, a adição do extrato de cogumelo reduziu a formação de dienos conjugados quando comparados ao óleo de soja isento de antioxidantes, sendo que ao final do teste acelerado de estufa essa redução foi de aproximadamente $67 \%$ de formação de dienos conjugados.

Observa-se que a formação de dienos conjugados foi crescente ao longo do tempo em todos os tratamentos. Ao final do período de estocagem (16 dias) o extrato de cogumelo apresentou a mesma característica encontrada nas análises anteriores, ou seja, ser mais eficiente que o BHT e menos que o TBHQ.

\section{CONCLUSÕES}

O extrato metanólico-aquoso (1:1) de A. blazei, obtido em 6 horas de extração, apresentou maior rendimento e atividade antioxidante mais eficaz. A adição desse extrato ao óleo de soja resultou em proteção efetiva $(20,4 \mathrm{~h}$ de estabilidade oxidativa), sendo sua ação mais eficiente que o antioxidante sintético BHT (100 mg/kg) e menor que o TBHQ (50 mg/kg).

Conclusivamente, o extrato de cogumelo (EC) apresenta-se como um agente antioxidante natural promissor. No entanto, torna-se fundamental a investigação da sua ação em diferentes concentrações para que o cogumelo seja mais competitivo no mercado.

\section{AGRADECIMENTOS}

Ao Prof. Dr. Luiz Antonio Graciolli, da Faculdade de Engenharia de Ilha Solteira - UNESP, pela doação da amostra do cogumelo A. blazei.

\section{REFERÊNCIAS BIBLIOGRÁFICAS}

AMERICAN OIL CHEMISTS SOCIETY. Official methods and recommended practices of the American Oil Chemists Society. 3.ed. Illinois: Champaing, 1993.

ANGELO, P.M.; JORGE, N. Compostos fenólicos em alimentos: uma breve revisão. Revista do Instituto Adolfo Lutz, São Paulo, v.66, n.1, p.1-9, jan./abr. 2007.

BANZATTO, D.A.; KRONKA, S.N. Experimentação agrícola. 4.ed. Jaboticabal: Funep, 2006. 237p.

BRAGA, G.C.; EIRA, A.F.; CELSO, P.G.; COLAUTO, N.B. Manual do cultivo de Agaricus blazei "Cogumelo-dosol”. Botucatu: Fundação de Estudos e Pesquisas Agrícolas e Florestais, 1998. 44p.
BRAND-WILLIAMS, W.; CUVELIER, M.E.; BERSET, C. Use of a free radical method to evaluate antioxidant activity. Lebensmittel Wissenschaft und Technologie Food Science and Technology, London, v.28, n.1, p.25-30, 1995.

BRASIL. Resolução n 482, de 23 de setembro de 1999. Regulamento técnico para fixação de identidade e qualidade de óleos e gorduras vegetais. Diário Oficial da União, Brasília, DF, v.196, 13 out. 1999. Seção I, p.8287.

COUTINHO, L.N. Cultivo de espécies de cogumelo comestíveis. Disponível em: $<\mathrm{h} t \mathrm{t} \mathrm{p}: / / \mathrm{www}$.geocities.comesabio.geo/cogumelo/agaricus.htm $\lambda$. Acesso em: $20 \mathrm{dez}$. 2007 .

DAPKEVICIUS, A.; VENSKUTONIS, R.; BEEK, T.A. van; LINSSEN, J.P.H. Antioxidant activity of extracts obtained by different isolation procedures from some aromatic herbs grown in Lithuania. Journal of the Science of Food and Agriculture, London, v.77, n.1, p.140-146, 1998.

DI PIERO, R.M. Potencial dos cogumelos Leninula edodes (shitake) e Agaricus blazei (Cogumelo-do-Sol) no controle de doenças em plantas de pepino, maracujá e tomate, e a purificação parcial dos compostos biologicamente ativos. 2003. 171f. Tese (Doutorado em Fitopatologia)-Escola Superior de Agricultura "Luiz de Queiroz”, Universidade de São Paulo, Piracicaba, 2003.

ELMASTAS, M.; ISILDAK, O.; TURKEKUL, I.; TEMUR, N. Determination of antioxidant activity and antioxidant compounds in wild edible mushrooms. Journal of Food Composition and Analysis, Amsterdam, v.20, n.3/4, p.337-345, 2007.

FURLANI, R.P.Z.; GODOY, H.T. Valor nutricional de cogumelos comestíveis: uma revisão. Revista do Instituto Adolfo Lutz, São Paulo, v.64, n.2, p.149-154, 2005.

GÁMEZ-MEZA, N.; NORIEGA-RODRÍGUEZ, J.A.; MEDINA-JUÁREZ, L.A.; ORTEGA-GARCÍA, J.; CÁZAREZ-CASANOVA, R.; ANGULO-GUERRERO, O. Antioxidant activity in soybean oil of extracts from Thompson Grape Bagasse. Journal of the American Oil Chemists Society, Chicago, v.76, n.12, p.1445-1447, Dec. 1999. 
JULKUNEN-TIITTO, R. Phenolic constituents in the leaves of northern willows: methods for the analysis of certain phenolic. Journal of Agricultural and Food Chemistry, Easton, v.33, n.2, p.213-217, 1985.

KAWAGISHI, H.; KANAO, T.; INAGAKI, R.; MIZUNO, T.; SHIMURA, K.; ITO, H.; HAGIWARA, T.;

NAKAMURA, T. Formolysis of a potent antitumor (1à6)-â-D-glucan-protein complex from Agaricus blazei fruiting bodies and antitumor activity of resulting products. Carbohydrate Polymers, Barking, v.12, n.4, p.393-403, 1990

KEINÄNEN, M. Comparison of methods for the extraction of flavonoids from birch leaves (Betula pendula Roth.) carried out using high-performance liquid chromatography. Journal of Agricultural and Food Chemistry, Easton, v.41, n.11, p.1986-1990, 1993.

MIZUNO, T.; HAGIWARA, T.; NAKAMURA, T.; ITO, H.; SHIMURA, K.; SUMIYA, T.; ASAKURA, A.

Antitumor activity and some properties of water-soluble polysacharides from "Himematsutake", the fruiting body of Agaricus blazei Murrill. Agricultural and Biological Chemistry, Tokyo, v.54, n.11, p.2889-2896, 1990.

NAKAJIMA, A.; ISHIDA, T.; KOGA, M.; TAKEUCHI, T.; MAZDA, O.; TAKEUCHI, M. Effect of hot water extract from Agaricus blazei Murill on antibodyproducing cells in mice. International

Immunopharmacology, Amsterdam, v.2, n.8, p.1205-1211, July 2002.

SINGLETON, V.L.; ROSSI, J.A. Colorimetry of total phenolics with phosphomolybdic-phosphotungstic acid reagents. American Journal of Enology and Viticulture, Davis, v.16, n.3, p.144-158, 1965.

TAKAKU, T.; KIMURA, Y.; OKUTA, H. Isolation of an antitumor compound from Agaricus blazei Murrill and its mechanism of action. Journal of Nutrition, Philadelphia, v.131, n.5, p.1409-1413, 2001.

TEIXEIRA, E.M. Cogumelo do sol: Algaricus blazei. Jaboticabal: Funep, 1999. 38p.

TSAI, S.; TSAI, H.; MAU, J. Antioxidant properties of Agaricus blazei, Agrocybe cylindracea and Boletus edulis. Lebensmittel Wissenschaft und Technologie Food Science and Technology, London, v.40, n.8, p.13921402, 2007.

UNIVERSIDADE ESTADUAL PAULISTA. Faculdade de Ciências Agrárias e Veterinárias. ESTAT - Sistema para Análises Estatísticas. Versão 2.0. Jaboticabal, 1999. 1 disquete. 